\title{
Quantitative evaluation of corneal epithelial edema after cataract surgery using corneal densitometry: a prospective study
}

\author{
Sho Ishikawa ${ }^{1,2^{*}}$, Naoko Kato ${ }^{1,2}$ and Masaru Takeuchi ${ }^{2}$
}

\begin{abstract}
Purpose: The optical density of the cornea can be evaluated quantitatively by "densitometry" using a rotating Scheimpflug camera. Densitometry allows evaluation of corneal opacity in the anterior segment of the eye by quantitative measurement of scattering light. In the present investigation, we evaluate quantitatively minimal subclinical corneal edema after cataract surgery using densitometry.

Methods: Fifty four eyes of 34 patients who underwent cataract surgery were enrolled. Measurement of corneal density was performed using Pentacam ${ }^{\oplus}$ before and on days 1, 3 and 7 after surgery.

Results: Densitometry scores increased from $18.12 \pm 1.76$ before cataract surgery to $21.03 \pm 3.84$ on day $1(P<0.001)$ and $19.90 \pm 2.46$ on day $3(P=0.018)$, but recovered to $19.44 \pm 1.58$ on day $7(P=0.131)$. Total corneal thickness was $549.1 \pm 32.7 \mu \mathrm{m}$ before surgery and increased to $582.7 \pm 46.3 \mu \mathrm{m}$ on day $1(P=0.001)$, but recovered to $566.4 \pm 29.7 \mu \mathrm{m}$ on day $3(P=0.097$ ). Densitometry reading correlated positively with corneal thickness (correlation coefficient $=0.13$, $P=0.003)$.
\end{abstract}

Conclusions: Densitometry is useful to detect corneal edema that is not detectable by slit-lamp examination.

Keywords: Densitometry, Corneal edema, Cataract surgery

\section{Introduction}

The Pentacam ${ }^{\bullet}$ (Oculus, Wetzlar, Germany), a corneal tomography using a rotating Scheimpflug camera is a diagnostic tool for the anterior segment of the eye, allows quantitative evaluation of the optical media as "densitometry". The densitometry program that measures scattering light allows quantitative and objective measurement of opacities within the anterior segment of the eyes. Since Smith et al. [1] first reported on the evaluation of healthy cornea by Scheimpflug imaging, densitometry has been used for objective assessment of cataract-associated media opacification.

Several clinical studies have reported the usefulness of densitometry for quantitative evaluation of corneal opacification in various conditions such as corneal dystrophy [2], mucopolysaccharidosis [3], corneal haze after

\footnotetext{
* Correspondence: sho_ijp@yahoo.co.jp

${ }^{1}$ Department of Ophthalmology, Saitama Medical University, 38 Morohongo, Moroyama, Saitama 350-0495, Japan

${ }^{2}$ Department of Ophthalmology, National Defense Medical College, 3-2

Namiki, Tokorozawa, Saitama 359-8216, Japan
}

corneal cross linking for keratoconus $[4,5]$ or keratectasia [4], laser in situ keratomileusis [6, 7], photorefractive keratectomy [8,9], and lamellar keratoplasty [10, 11], corneal infection [12], after Descemet's stripping automated endothelial keratoplasty [13] or penetrating keratoplasty [14], increase in corneal light scattering has been detected by densitometry even in cases clinically assessed to be clear by slit-lamp microscopy, indicating the potential use of densitometry for objective measurements as an adjuvant to slit-lamp examination. However, there is no report that densitometry can be used as an indicator of minimal corneal edema.

Phacoemulsification is a standard procedure for cataract surgery, and is the most common procedure performed in recent decades. Even in uneventful cataract surgeries, various intraoperative factors such as ultrasound energy emitted by phacoemulsification, greater infusion volume, mechanical contact of nuclear fragments with the corneal endothelium, and high intraocular pressure may cause

(c) The Author(s). 2018 Open Access This article is distributed under the terms of the Creative Commons Attribution 4.0 International License (http://creativecommons.org/licenses/by/4.0/), which permits unrestricted use, distribution, and reproduction in any medium, provided you give appropriate credit to the original author(s) and the source, provide a link to the Creative Commons license, and indicate if changes were made. The Creative Commons Public Domain Dedication waiver (http://creativecommons.org/publicdomain/zero/1.0/) applies to the data made available in this article, unless otherwise stated. 
subclinical corneal edema, although no significant findings are detected by slit-lamp examination.

The purpose of the present study was to detect quantitatively serial changes of backward light scattering after cataract surgery using the densitometry.

\section{Materials and methods}

Fifty four eyes of 34 patients (aged $71 \pm 8.4$ years, 18 males and 16 females) who underwent cataract surgery at the Department of Ophthalmology, National Defense Medical College between July 2012 and October 2013 were enrolled; a prospective study. All eyes had nuclear cataract of grade 2 or above were included. Eyes with ocular surface diseases before surgery, such as dry eye and superficial punctate keratopathy, were excluded.

In addition to routine ophthalmic examinations, we assessed corneal densitometry readings and corneal thickness by Pentacam ${ }^{\circ}$ before cataract surgery and on days 1,3 and 7 after surgery. Examination with Penta$\mathrm{cam}^{\circ}$ was conducted as recommended in the instruction manual. After the patient had placed his/her head on the instrument's head and chin rests, the Pentacam ${ }^{\circ}$ was aligned so that a dim, blue light illuminated the cornea. The instrument was aligned so that the patient's eye and the live Scheimpflug image came into view. The apex of the cornea was marked by positioning a yellow circle, and the patient was asked to open the eye widely. Twenty-five Scheimpflug images were taken automatically in three-dimensional scan mode. The instrument allows full-thickness corneal haze evaluation, and shows the measured maximum density values on a densitogram on a scale from 0 to 100; 0 indicating no clouding and 100 indicating completely opaque.

We measured corneal density with the cornea density mode of Pentacam ${ }^{\circ}$. The cornea is divided into 12 portions according to the zone and the depth; namely, four zones in concentric circles from the corneal apex (central $2 \mathrm{~mm}$ zone, surrounding 2-6 $\mathrm{mm}$ annulus, $6-10 \mathrm{~mm}$ annulus, and 10-12 $\mathrm{mm}$ annulus) and three depths (anterior layer: from the corneal surface to a depth of $120 \mu \mathrm{m}$, center layer: between the anterior and posterior layers, and posterior layer: the deepest $60 \mu \mathrm{m})$. The densitometry value is expressed as the average score in each portion. We used the corneal densitometry score in the central 2 $\mathrm{mm}$ zone and the anterior layer $(0-120 \mu \mathrm{m}$ depth) for analysis (Fig. 1). Before the surgery, the lid skin was scrubbed with $10 \%$ povidone-iodine (Meiji Seika, Tokyo, Japan) and the conjunctiva and cornea within the operative field were disinfected with $1 \%$ povidone-iodine. For topical anesthesia, $4 \%$ lidocaine eye drops were instilled onto the operated eye. All cataract surgeries were performed by the same surgeon (S.I) using phacoemulsification and aspiration technique via a small incision (2.4 $\mathrm{mm}$ ). The Infiniti (Alcon, Fort Worth, Texas) was used as the phacoemulsification instrument. The setting of the instrument was as follows: irrigation pressure 80-90 $\mathrm{cmH} 2 \mathrm{O}$, aspiration rate $20-25 \mathrm{~mm} / \mathrm{min}$, aspiration pressure $40-350 \mathrm{mmHg}$, and phacopower $40-60 \%$.

The study protocol was approved by the ethical committee of the National Defense Medical College and the research was conducted according to the tenets of the Declaration of Helsinki.

\section{Statistical analysis}

JMP software version 10 was used for the statistical analysis. Friedman's test with Bonferroni correction as multiple comparison procedure was used as a nonparametric test to compare corneal densitometry score and corneal thickness. The Spearman's correlation coefficient was used to analyze correlation between corneal densitometry score and corneal thickness. $P$ values less than 0.05 were considered statistically significant.

\section{Results}

Fifty four eyes of 34 patients (aged $71 \pm 8.4$ years, 18 males and 16 females) were enrolled. All eyes had nuclear cataract of grade 2 or above. Sixteen eyes had posterior subcapsular opacity, 34 eyes had cortical opacity, and 4 eyes had mature cataract. All cataract surgeries were completed uneventfully, and no perioperative complications were observed. Best corrected visual acuity (BCVA) was improved in all eyes. The average BCVA (Log MAR) was $0.33 \pm 0.38$ before surgery and $0.05 \pm$ 0.19 on day 1 after surgery. Intraocular pressure was within normal range in all eyes before $(10-19 \mathrm{mmHg})$ and after (7-17 $\mathrm{mmHg}$ ) surgery (Table 1). Slit-lamp examination detected minimum fold of the Descemet's membrane after surgery in 6 of 54 eyes.

Densitometry readings in the central $2 \mathrm{~mm}$ zone within the anterior layer was $18.12 \pm 1.76$ before surgery, and increased significantly to $21.03 \pm 3.84$ on day $1(P<0.001)$ and $19.90 \pm 2.46$ on day $3(P=0.017)$ but recovered to $19.44 \pm 1.58$ on day $7(P=0.131)$ after surgery (Fig. 1a). Densitometry readings in the $2-6 \mathrm{~mm}$ annulus within the anterior layer was $19.11 \pm 4.66$ before surgery and increased significantly to $22.18 \pm 7.40$ on day $1(P=0.046)$ but declined to $20.73 \pm 4.60$ on day $3(P=0.296)$ and $21.39 \pm 4.86$ on day $7(P=0.183)$ after surgery (Fig. $1 \mathrm{e})$. In the center layer, the densitometry readings showed no significant changes both in the central $2 \mathrm{~mm}$ zone and the 2-6 $\mathrm{mm}$ annulus throughout the study period (Fig. 1b and f). In the posterior layer, densitometry readings in the central $2 \mathrm{~mm}$ zone increased significantly only on day 1 after surgery $(10.8 \pm 1.3$ to $12.4 \pm 2.9, P=0.003)$, but returned to preoperative value on day 3 after surgery (Fig. $1 \mathrm{c}$ and $g$, Fig. 2, Additional file 1).

Total corneal thickness (mean \pm standard deviation) at the corneal apex was $549.1 \pm 32.7 \mu \mathrm{m}$ before surgery 


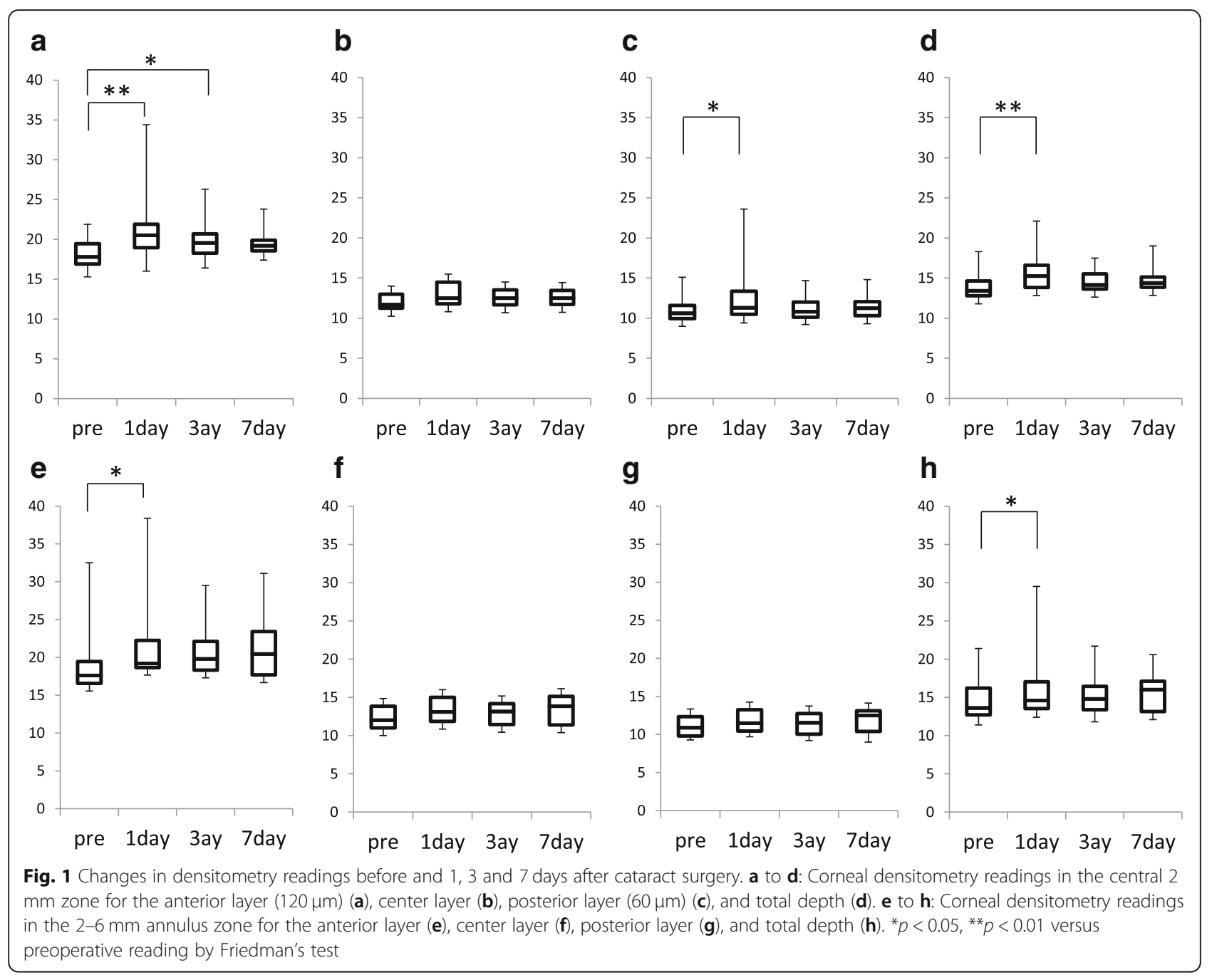

and increased to $582.7 \pm 46.3 \mu \mathrm{m}$ on day 1 after surgery $(P=0.001)$, but recovered to $566.4 \pm 29.7 \mu \mathrm{m}$ on day $3(P=0.097)$ and $559.4 \pm 32.4 \mu \mathrm{m}$ on day $7(P=0.400)$ after surgery (Fig. 3).

Densitometry readings in the central $2 \mathrm{~mm}$ zone for the anterior layer correlated positively with the corneal thickness (correlation coefficient $=0.36, P=0.003$ ), but the densitometry readings for the center and posterior layers and total depth did not correlate significantly with the corneal thickness (Fig. 4).

\section{Discussion}

In the present investigation, we used a rotating Scheimpflug camera to assess the serial changes of corneal densitometry from before cataract surgery to 7 days after surgery. Our results showed transient increases in densitometry reading after uneventful cataract surgeries and a significant correlation between densitometry readings and corneal thickness. These findings may indicate that subclinical corneal epithelial or stromal edema occurs and causes light scattering shortly after cataract surgery.

Table 1 Changes in BVCA, corneal thickness, and intraocular pressure

\begin{tabular}{lllll}
\hline & Preoperative & Postoperative & & \\
\cline { 3 - 4 } & & Day1 & Day3 & $0.008 \pm 0.151^{*}$ \\
\hline BVCA (LogMAR) & $0.332 \pm 0.382$ & $0.050 \pm 0.186^{*}$ & & $561.1 \pm 31.9$ \\
Central corneal thickness $(\mu \mathrm{m})$ & $550.1 \pm 32.4$ & $588.3 \pm 53.9^{* *}$ & $567.8 \pm 29.9$ & $1.5 \pm 3.1^{*}$ \\
Intraocular pressure $(\mathrm{mmHg})$ & $14.2 \pm 2.6$ & $13.2 \pm 3.1$ & $11.5 \pm 2.5^{*}$ \\
\hline BCVA
\end{tabular}




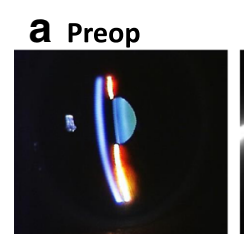

b

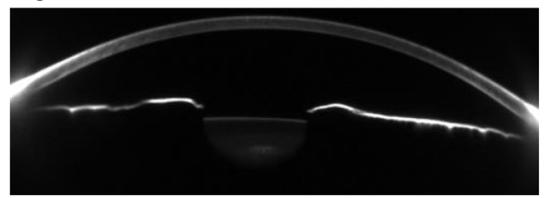

d 1 day postop $\mathrm{e}$
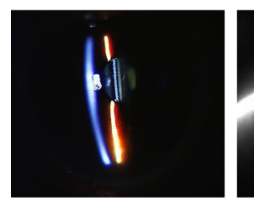

g

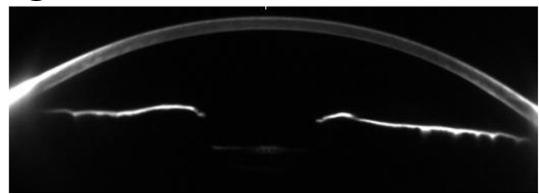

c

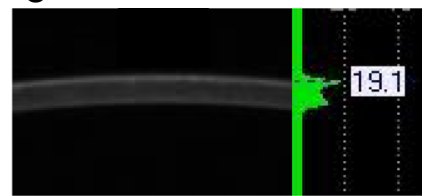

f

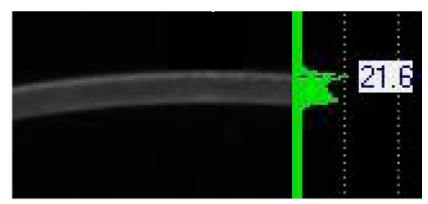

h

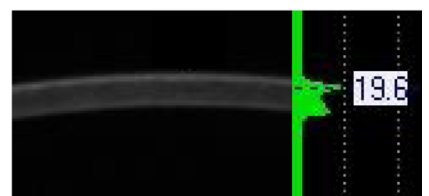

Fig. 2 Representative slit-lamp photographs (left), Scheimpflug images (center), and densitometry readings (right) of central cornea before cataract surgery (a) and on day 1 (b) and day 3 after surgery (c). Slit-lap examination reveals no abnormal finding before (a) and 1 day after surgery (b). Scheimpflug images show minimal opacity on day 1 and day 3 after surgery. Densitometry score is 19.1 before cataract surgery (a), increases to 21.6 on day 1 (b) and recovers to 19.6 on day 3 after surgery $(\mathbf{c})$

In this study, densitometry readings in the anterior layer were higher than that in the posterior layer. A similar tendency was also reported in previous investigations using confocal microscopy [15] or scatterometer [16]. According to previous evaluations using atomic force microscopy [17] and second harmonic generation microscopy [18, 19], collagen fibers are interwoven in three dimensions and adhere densely to Bowman's layer and fiber density is less dense in the anterior stroma than in the posterior stroma in healthy cornea [18]. The

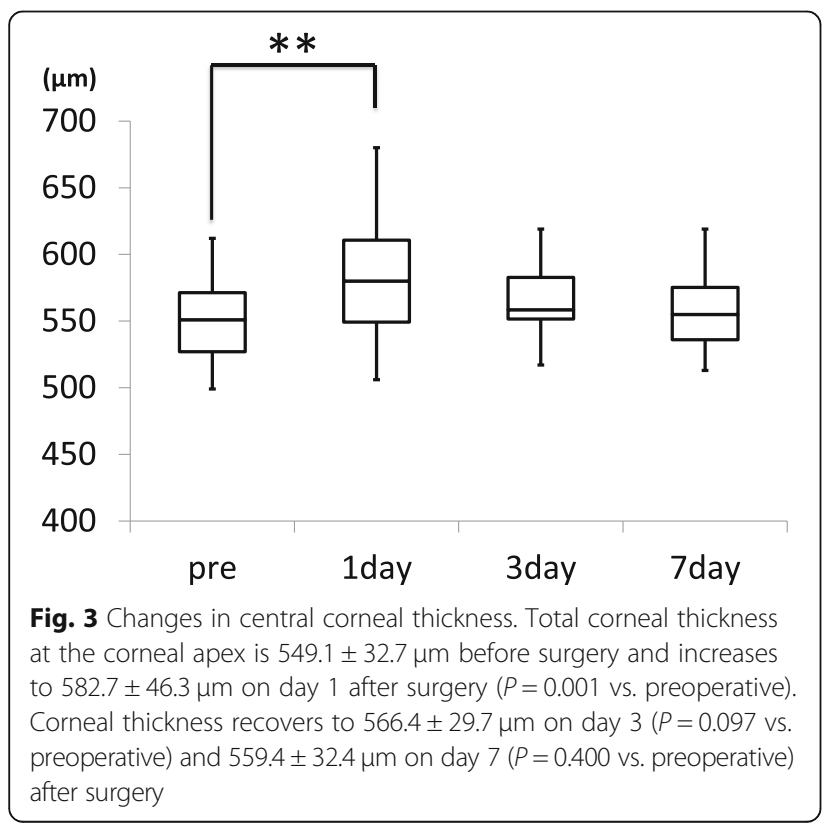

difference in densitometry readings between anterior and posterior corneal layer may reflect the difference in stromal collagen structure between different layers.

Ní Dhubhghaill et al. [20] evaluated corneal densitometry in normal Caucasian eyes using Scheimpflug camera. According to their study, densitometry reading in the central $2 \mathrm{~mm}$ zone in the anterior layer (up to $120 \mu \mathrm{m}$ in depth) was $22.87 \pm 2.91$, and densitometry reading in the central $2 \mathrm{~mm}$ zone for total depth was $16.76 \pm 1.87$. In the present study, however, the densitometry reading in the central $2 \mathrm{~mm}$ zone was $18.1 \pm 1.8$ in the anterior layer, and was $14.0 \pm 1.7$ for total corneal depth. We speculate that the difference in scores may reflect racial difference, because all patients enrolled in our study were Asian. Corneal thickness was reported to differ between races, and the central corneal thickness is thicker in Caucasian eyes compared to Asian eyes [2124]. Age also changes the value of densitometry. The densitometry readings of central and posterior layer increased with age but not anterior layer [25]. According to their study, densitometry reading of 60-69 years old in the central $2 \mathrm{~mm}$ zone in the anterior layer was 18.31 , center was 15.21 , posterior was 12.23 and total depth was 15.37 in Caucasian eyes. In this study, light scattering may increase when the number of corneal collagen fibers is larger, possibly resulting in increase in densitometry reading. It is reported that the ability to detect changes in backscatter was superior with Scheimpflug camera to confocal microscopy [26].

Another possibility is that we excluded eyes with corneal surface diseases including dry eye and superficial 


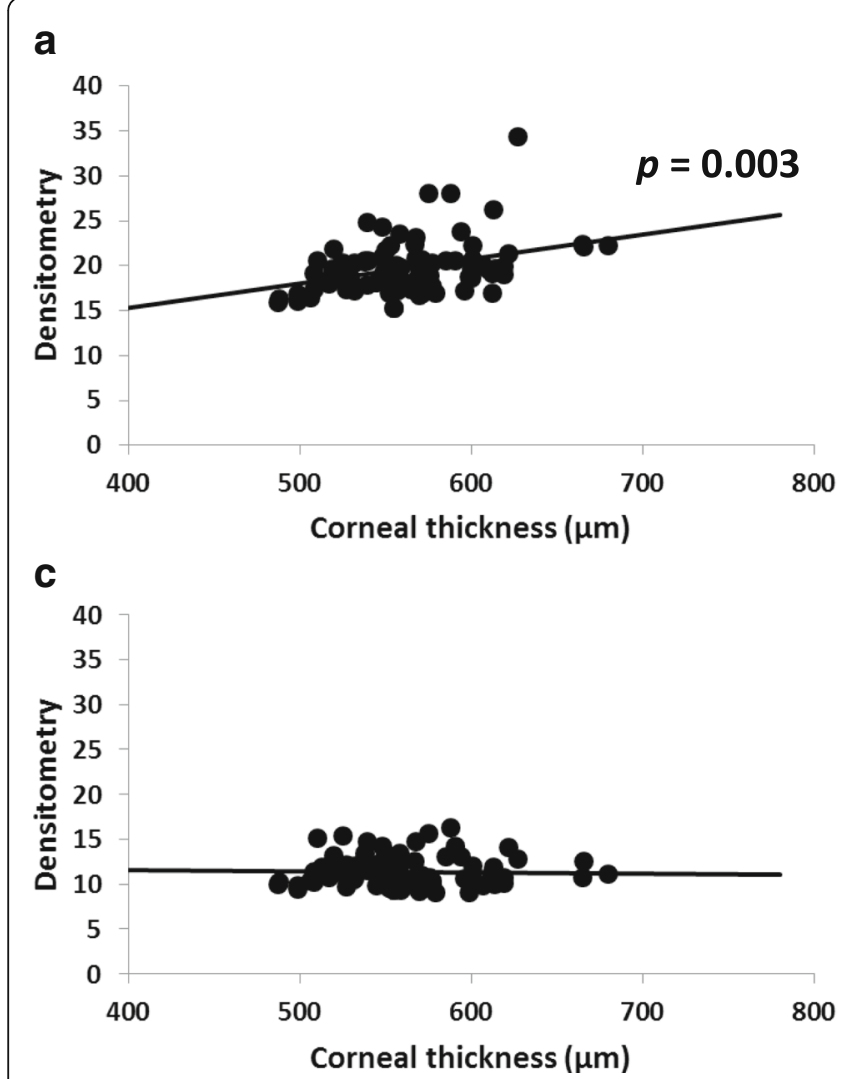

b

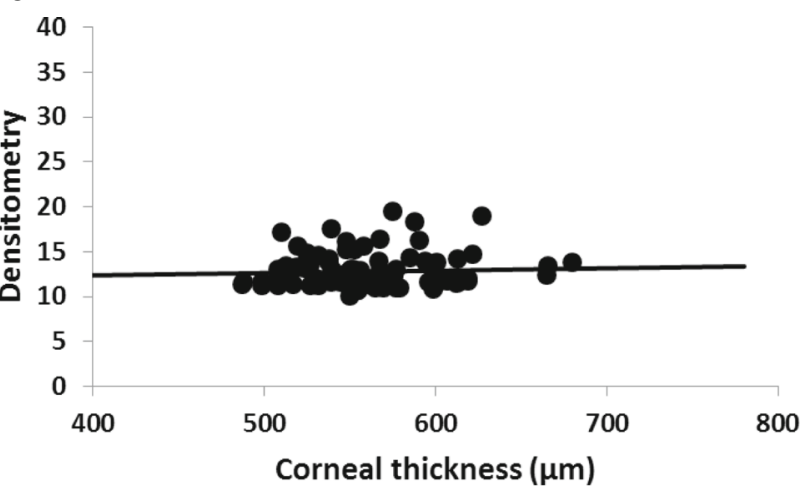

d

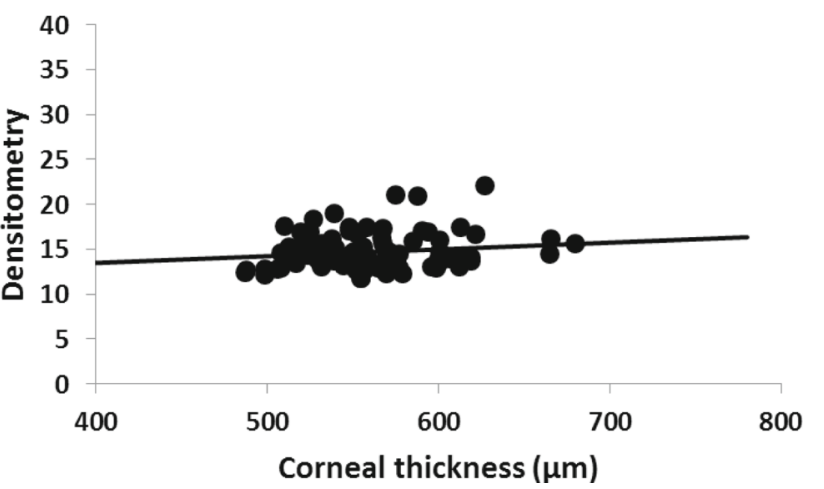

Fig. 4 Correlation of corneal thickness with densitometry score for the anterior layer (a), center layer (b), posterior layer (c), and total depth (d). Densitometry reading for the anterior layer correlates positively with central corneal thickness [correlation coefficient $(r)=0.36, P=0.003$ ]. No correlation is observed for the center layer $(\mathbf{b} ; r=0.05, p=0.87)$, the posterior layer $(\mathbf{c} ; r=0.02, p=0.47)$, and total depth $(\mathbf{d} ; r=0.14, P=0.44)$, ${ }^{*} P<0.05$ by Spearman's correlation coefficient

punctate keratopathy both before and after the surgery in the present investigation. Such ocular surface distintegrity could cause light scattering and possibly influence the densitometry readings. The densitometry readings might increase due to corneal epithelial damage, while increase of densitometry readings in the anterior layer cannot distinguish the light scattering of the epithelial or superficial stromal layer. There are some reports that some drugs using during surgery caused corneal epithelial damage. 5\% povidone iodine may cause corneal epithelial damage [27] and $10 \%$ povidone iodine with presurgical skin antiseptics are toxic for cornea [28]. We used $1 \%$ povidone iodine the conjunctiva and cornea within the operative field, but $10 \%$ povidone iodine was used with skin. We cannot deny possibility that $10 \%$ povidone iodine has exposed to the cornea and affected densitometry readings. Topical anesthesia may also corneal epithelial damage. When the cornea becomes edematous, intra- and inter-cellular fluid accumulation occurs in the epithelial layer, and is followed by subsequent accumulation of fluid within and between the stromal lamellae within the underneath stroma. These edematous changes of epithelial and underneath stromal structure may cause light scattering, which is partially reflected by the increase in densitometry reading.

The correlation between corneal thickness and light scattering of the cornea was first reported in 1982 by Olsen [29], who applied slit-lamp fluorophotometry to measure light scattering of the whole cornea in eyes that underwent cataract surgery within 1 week prior to study. He speculated that light scattering increases sharply as the tissue swells; the space between collagen fibrils becomes less regular, thereby increasing the amount of light scattered. These findings may support our theory that the elevation of densitometry reading is due to increase in light scattering caused by corneal epithelial and stromal edema, although the surgical procedure used in Olsen's study was supposed to be extracapsular extraction, which is more invasive than the small incision phacoemulsification used in the present study.

Interestingly, corneal edema occurred shortly after surgery not only around the incision but also in central cornea. However, the edema was transient and improved quickly in subsequent several days. The densitometry 
readings in the central $2 \mathrm{~mm}$ zone improved faster than in the surrounding $2-6 \mathrm{~mm}$ zone, probably reflecting centripetal processes of wound healing [30, 31] and endothelial cell migration [32]. Further investigations on the topographical changes of densitometry reading and corneal edema may contribute to elucidate the mechanisms of water distribution and its relation with wound healing in the cornea.

This study had some limitations. First, we did not use confocal microscopy in this study, so we cannot confirm more detailed corneal change. Second, we did not assessed quality of vision such as glare, halos and blurring. None of the patients complained symptoms after the surgery, but there is a possibility that patient did not feel symptoms the several days after surgery. Third, corneal densitometry readings of posterior segment are influenced from the anterior corneal haze. As the anterior densitometry readings increases, the values of central and posterior densitometry readings may be inaccurate. In this study, there was no patient who had very high densitometry readings compared to previous reports such as corneal surgery [8-11], densitometry readings of anterior segment may influence the readings of central and posterior segment.

\section{Conclusions}

In summary, densitometry using the Scheimpflug device for measuring corneal scattering may be a useful tool to detect minimal subclinical corneal edema usually undetectable by slit-lamp examination. There is a possibility that densitometry helps to detect subtle edema of the cornea particularly in experimental studies.

\section{Additional file}

Additional file 1: Corneal densitometry readings pre and postoperative surgery. Densitometry readings in the central $2 \mathrm{~mm}$ zone within the anterior layer before and postoperative on day 1 , day 3 and day 7 were $18.1 \pm 1.8,21.3 \pm 3.8,19.9 \pm 2.5,19.4 \pm 1.6$. Densitometry readings in the 2-6 $\mathrm{mm}$ annulus within the anterior layer before and postoperative on day 1 , day 3 and day 7 were $19.1 \pm 4.7,22.1 \pm 7.4,20.7 \pm 4.6,21.3 \pm 4.9$. Densitometry readings in the central $2 \mathrm{~mm}$ zone within the center layer before and postoperative on day 1 , day 3 and day 7 were $12.2 \pm 1.5,13.7$ $\pm 2.6,12.8 \pm 1.5,13.0 \pm 1.8$. Densitometry readings in the $2-6 \mathrm{~mm}$ annulus within the center layer before and postoperative on day 1 , day 3 and day 7 were $12.6 \pm 2.0,14.2 \pm 3.8,13.1 \pm 1.8,13.5 \pm 2.1$. Densitometry readings in the central $2 \mathrm{~mm}$ zone within the posterior layer before and postoperative on day 1 , day 3 and day 7 were $10.8 \pm 1.3,12.4 \pm 2.9$, $11.2 \pm 1.4,11.4 \pm 1.5$. Densitometry readings in the $2-6 \mathrm{~mm}$ annulus within the posterior layer before and postoperative on day 1 , day 3 and day 7 were $11.3 \pm 1.6,12.3 \pm 2.4,11.5 \pm 1.5,11.9 \pm 1.7$. Densitometry readings in the central $2 \mathrm{~mm}$ zone before and postoperative on day 1, day 3 and day 7 were $14.0 \pm 1.7,15.7 \pm 2.8,14.6 \pm 1.6,14.8 \pm 1.6$. Densitometry readings in the $2-6 \mathrm{~mm}$ annulus before and postoperative on day 1 , day 3 and day 7 were $14.6 \pm 2.8,16.4 \pm 4.3,15.1 \pm 2.3,15.6 \pm 2.6$. (DOCX $82 \mathrm{~kb}$ )

\section{Abbreviation}

BCVA: Best corrected visual acuity

\section{Acknowledgements}

The authors thank to Kanako Tonegawa for her assistance for helping medical examination.

\section{Funding}

No funding was received by any of the authors for the writing of this manuscript.

\section{Availability of data and materials}

The datasets used and/or analyzed during the current study are available from the corresponding author on reasonable request.

\section{Authors' contributions}

All authors made significant contribution for the design of the study. SI drafted the manuscript and performed the literature review and participated in information gathering and editing. NK and MT made contributions to analysis and interpretation of data. NK and MT conceived the idea and supervised writing of the case report. NK revised this manuscript critically for important intellectual content. MT made substantial contributions to conception and design. All authors read and approved the final manuscript.

\section{Ethics approval and consent to participate}

This study was performed in accordance with the Declaration of Helsinki and was approved by the ethical committee of the National Defense Medical College. Informed consent was obtained from all subjects after the aims and nature of the study were explained to the participants.

\section{Consent for publication}

Not applicable.

\section{Competing interests}

The authors declare that they have no competing interests.

\section{Publisher's Note}

Springer Nature remains neutral with regard to jurisdictional claims in published maps and institutional affiliations.

Received: 2 February 2018 Accepted: 5 December 2018

Published online: 20 December 2018

\section{References}

1. Smith GT, Brown NA, Shun-Shin GA. Light scatter from the central human cornea. Eye (Lond). 1990:4(4):584-8.

2. Ha BJ, Kim TI, Choi SI, Stulting RD, Lee DH, Kim EK, et al. Mitomycin C does not inhibit exacerbation of granular Corneal dystrophy type ii induced by refractive surface ablation. Cornea. 2010;29:490-6.

3. Elflein HM, Hofherr T, Berisha-Ramadani F, Weyer V, Lampe C, Pitz S, et al. Measuring Corneal clouding in patients suffering from Mucopolysaccharidosis with the Pentacam densitometry Programme. Br J Ophthalmol. 2013;97:829-33.

4. Greenstein SA, Fry KL, Bhatt J, Hersh PS. Natural history of Corneal haze after collagen crosslinking for keratoconus and Corneal ectasia: Scheimpflug and biomicroscopic analysis. J Cataract Refract Surg. 2010;36:2105-14.

5. Gutierrez R, Lopez I, Villa-Collar C, Gonzalez-Meijome JM. Corneal transparency after cross-linking for keratoconus: 1-year follow-up. J Refract Surg. 2012;28:781-6.

6. Rozema JJ, Trau R, Verbruggen KH, Tassignon MJ. Backscattered light from the cornea before and after laser-assisted subepithelial keratectomy for myopia. J Cataract Refract Surg. 2011;37:1648-54

7. Fares U, Otri AM, Al-Aqaba MA, Faraj L, Dua HS. Wavefront-optimized excimer laser in situ Keratomileusis for myopia and myopic astigmatism: refractive outcomes and Corneal densitometry. J Cataract Refract Surg. 2012; 38:2131-8.

8. Takacs Al, Mihaltz K, Nagy ZZ. Corneal density with the Pentacam after photorefractive keratectomy. J Refract Surg. 2011;27:269-77.

9. Cennamo G, Forte R, Aufiero B, La Rana A. Computerized Scheimpflug densitometry as a measure of Corneal optical density after excimer laser refractive surgery in myopic eyes. J Cataract Refract Surg. 2011;37:1502-6.

10. Koh S, Maeda N, Nakagawa T, Nishida K. Quality of vision in eyes after selective lamellar Keratoplasty. Cornea. 2012;31(Suppl 1):S45-9. 
11. Bhatt UK, Fares U, Rahman I, Said DG, Maharajan SV, Dua HS. Outcomes of deep anterior lamellar Keratoplasty following successful and failed 'Big bubble. Br J Ophthalmol. 2012;96:564-9.

12. Otri AM, Fares U, Al-Aqaba MA, Dua HS. Corneal densitometry as an Indicator of Corneal health. Ophthalmology. 2012;119:501-8.

13. Patel SV, Baratz KH, Hodge DO, Maquire LJ, Mclaren JW. The effect of Corneal light scatter on vision after Descemet stripping with endothelial Keratoplasty. Arch Ophthalmol. 2009;127:153-60.

14. Patel SV, McLaren JW, Hodge DO, Bourne WM. The effect of Corneal light scatter on vision after penetrating Keratoplasty. Am J Ophthalmol. 2008;146:913-9.

15. Hillenaar T, Cals RH, Eilers PH, Wubbels RJ, van Cleynenbreugel H, Remeijer L. Normative database for Corneal backscatter analysis by in vivo confocal microscopy. Invest Ophthalmol Vis Sci. 2011;52:7274-81.

16. Patel SV, Winter EJ, McLaren JW, Bourne WM. Objective measurement of backscattered light from the anterior and posterior cornea in vivo. Invest Ophthalmol Vis Sci. 2007:48:166-72.

17. Meek KM, Corneal FNJ. Scleral collagens--a Microscopist's perspective. Micron. 2001;32:261-72.

18. Morishige N, Takagi Y, Chikama T, Takahara A, Nishida T. Three-dimensional analysis of collagen lamellae in the anterior stroma of the human cornea visualized by second harmonic generation imaging microscopy. Invest Ophthalmol Vis Sci. 2011;52:911-5.

19. Ruberti JW, Roy AS, Roberts CJ. Corneal Biomechanics and Biomaterials. Annu Rev Biomed Eng. 2011;13:269-95.

20. Ni Dhubhghaill S, Rozema JJ, Jongenelen S, Ruiz Hidalgo I, Zakaria N, Tassignon MJ. Normative values for Corneal densitometry analysis by Scheimpflug optical assessment. Invest Ophthalmol Vis Sci. 2014;55:162-8.

21. Semes L, Shaikh A, McGwin G, Bartlett JD. The relationship among race, Iris color, central Corneal Thickness, and Intraocular Pressure. Optom Vis Sci. 2006;83:512-5.

22. Muir KW, Duncan L, Enyedi LB, Freedman SF. Central Corneal Thickness in children: racial differences (black vs. white) and correlation with measured intraocular pressure. J Glaucoma. 2006;15:520-3.

23. Tomidokoro A, Araie M, Iwase A. Corneal Thickness and Relating factors in a population-based study in Japan: the Tajimi study. Am J Ophthalmol. 2007; 144:152-4.

24. Suzuki S, Suzuki Y, Iwase A, Araie M. Corneal Thickness in an Ophthalmologically Normal Japanese population. Ophthalmology. 2005;112:1327-36.

25. Alzahrani K, Carley F, Brahma A, Morley D, Hillarby MC. Corneal clarity measurements in healthy volunteers across different age groups: observational study. Medicine (Baltimore). 2017;96:e8563.

26. Mclaren JW, Wacker K, Kane KM, Patel SV. Measuring Corneal haze by using Scheimpflug photography and confocal microscopy. Cornea. 2016; 57:227-35.

27. Ridder WH 3rd, Oquindo C, Dhamdhere K, Burke J. Effect of povidone iodine $5 \%$ on the cornea, vision, and subjective comfort. Optom Vis Sci. 2017:94:732-41.

28. Mac Rae SM, Brown B, Edelhauser HF. The corneal toxicity of presurgical skin antiseptics. Am J Ophthalmol. 1984;97:221-32.

29. Olsen T. Light scattering from the human cornea. Invest Ophthalmol Vis Sci. 1982;23:81-6

30. Mort RL, Ramaesh T, Kleinjan DA, Morley SD, West JD. Mosaic analysis of stem cell function and wound healing in the mouse Corneal epithelium. BMC Dev Biol. 2009;9:4.

31. Chang $C Y$, Green $C R$, McGhee $C N$, Sherwin T. Acute wound healing in the human central Corneal epithelium appears to be independent of Limbal stem cell influence. Invest Ophthalmol Vis Sci. 2008;49:5279-86.

32. He Z, Campolmi N, Gain P, Ha Thi BM, Dumollard JM, Thuret G, et al. Revisited microanatomy of the Corneal endothelial periphery: new evidence for continuous centripetal migration of endothelial cells in humans. Stem Cells. 2012;30:2523-34.

Ready to submit your research? Choose BMC and benefit from:

- fast, convenient online submission

- thorough peer review by experienced researchers in your field

- rapid publication on acceptance

- support for research data, including large and complex data types

- gold Open Access which fosters wider collaboration and increased citations

- maximum visibility for your research: over $100 \mathrm{M}$ website views per year

At $\mathrm{BMC}$, research is always in progress.

Learn more biomedcentral.com/submissions 